\title{
MENINGKATKAN PRODUKTIFITAS DIKALANGAN USIA LANJUT MENUJU LANSIA SEHAT, PRODUKTIF, SEJAHTERA DI PAGUYUBAN LANSIA ST. SIMEON PAROKI ST. LUKAS TEMINDUNG SAMARINDA
}

\author{
${ }^{1}$ Endang Wiwiek, ${ }^{2}$ Bonifasius Hat, ${ }^{3}$ Fransiska Keron Ola \\ 1,2,3 Program Studi DIII Keperawatan Stikes Dirgahayu Samarinda \\ Jalan Pasundan No.21 Telp (0541) 748335, Fax. (0541)748335 \\ email: endangwiwiekpurnama@gmail.com
}

\begin{abstract}
ABSTRAK
Meningkatnya jumlah lansia di Indonesia sebenarnya adalah indikator yang menunjukkan semakin sehatnya penduduk karena usia harapan hidupnya meningkat, meskipun disisi lain produktivitas mereka menurun. Tujuan dilaksanakan kegiatan ini adalah untuk meningkatkan derajat kesehatan serta kewaspadaan lansia di Paguyuban St.Simeon paroki St Lukas. Kegiatan ini meliputi, penyuluhan, pemeriksaan gula darah, tekanan darah, asam urat. Hasil pemerikaan menunjukkan bahwa Data yang didapat jumlah lansia yang terdaftar 134 orang, tekanan darah $\geq 140 / 100 \mathrm{mmHg}$ berjumlah 56 orang, gula darah sewaktu $\geq 120 \mathrm{mg} / \mathrm{dl}$ berjumlah 38 orang, asam urat $\geq 6 \mathrm{mg} / \mathrm{dl}$ berjumlah 119 orang, kolesterol $\geq 200 \mathrm{mg} / \mathrm{dl}$ berjumlah 87 orang. Tim pengabdian menyarankan agar anggota paguyuban lansia St.Simeon di paroki St. Lukas Samarinda dapat memeriksakan kesehatan secara rutin dan dapat mendeteksi risiko penyakit degeneratif secara dini
\end{abstract}

\section{Kata kunci: lansia, pemeriksaan, penyakit degeratif}

\begin{abstract}
The increasing number of elderly people in Indonesia is actually an indicator that shows the healthier population because their life expectancy increases, although on the other hand their productivity decreases. The purpose of this activity is to improve the degree of health and vigilance of the elderly in the St.Simeon Circle of St. Luke's parish. These activities include, counseling, checking blood sugar, blood pressure, gout. The results of the examination showed that the data obtained by the number of elderly registered 134 people, blood pressure $\geq 140 / 100 \mathrm{mmHg}$ amounted to 56 people, blood sugar when $\geq 120 \mathrm{mg} / \mathrm{dl}$ totaled 38 people, uric acid $\geq 6 \mathrm{mg} / \mathrm{dl}$ totaled 119 people, cholesterol $\geq 200 \mathrm{mg} / \mathrm{dl}$ totaling 87 people. The dedication team suggested that members of the St.Simeon elderly community in the parish of St. Lukas Samarinda can be checked regularly and can detect the risk of degenerative diseases early
\end{abstract}

\section{Keywords : elderly, examination, degenerative diseases}

\section{PENDAHULUAN}

Periode lansia merupakan periode kehidupan yang perlu mendapat perhatian terutama karena periode ini rentan terhadap penyakit degeneratif dankualitas hidup semakin menurun. Penurunan kualitas hidup ditandai dengan lansia yang tidak dapat melakukan sendiri aktivitas rutin seperti mandi atau memakai pakaian, tidak dapat menikmati aktivitas bersama anggota keluarga, tidak dapat melakukan sosialisasi dengan masyarakat lainnya seperti kegiatan keagamaan atau kegiatan sosial lainnya.

Indonesia merupakan 5 besar negara dengan jumlah lansia terbesar didunia. Diperkirakan jumlah lansia pada tahun 2025 jumlahnya adalah 36 juta jiwa (Depkes RI,2015). Setiap manusia akan melewati usia lanjut usia (lansia). Pada 
banyak populasi usia tua dapat dilewati dalam keadaan sehat, namun ada pula yang mlawatinya dalam keadaan sakit. Penyakit yang dialami pada lanjut usia bukan hanya perubahan dan penurunan fisik melainkan juga psikologi yang meliputi deprsi, stress dan gangguan lainnya.

Promosi kesehatan merupakan upaya yang dapat dilakukan agar masyarakat dalam suatu komnitas dapat meningkatkan derajat kesehatan serta memeliharanya (Notoatmodjo,2010).

Paguyuban St.Simeon paroki St Lukas bekerjasama dengan Rumah Sakit Dirgahayu dan STIKES Dirgahayu tidak mengalami masalah. Lansia di paguyuban St.Simeon memiliki pengetahuan yang cukup mengenai kualitas hidup pada lansia. Semakin meningkat derajat kesehatan masyarakat, maka akan semakin tinggi usia harapan hidup. Hal ini menyebabkan akan semakin besar pula populasi lansia. Periode lansia merupakan periode kehidupan yang perlu mendapat perhatian terutama karena periode ini rentan terhadap penyakit degeneratif dan kualitas hidup semakin menurun.

Penurunan kualitas hidup ditandai dengan lansia yang tidak dapat melakukan sendiri aktivitas rutin seperti mandi atau memakai pakaian, tidak dapat menikmati aktivitas bersama anggota keluarga, tidak dapat melakukan sosialisasi dengan masyarakat lainnya seperti kegiatan keagamaan atau kegiatan sosial lainnya. Kesehatan jasmani merupakan suatu suatu kesatuan yang tidak dapat dipisahkan dengan kegiatan olahraga. Masyarakat kadang lupa akan betapa pentingnya kesehatan apalagi di usia senja.

Pertambahan penduduk lanjut usia maka akan diikuti juga dengan masaah yang diakibatkan oleh berbagai penyebab dan aspek.. Lanjut usia termasuk dalam kelompok rentan dalam suatu komunitas. Hal ini menunjukan bahwa pentingnya perhatian bagi lanjut usia. Dalam kehidupan keluarga diIndonesia, lanjut usia merupakan figur yang dihormati dan harus dibahagiakan sesuai dengan budaya yang ada.

Didalam kehidupan bangsa, lanjut usia merupakan sumber daya bernilai karena pengetahuan, pengalaman hidup serta keaarifan yang dimiliki, yang sebenarnya dapat dimanfaatkan untuk meningkatkan mutu kehidupan keluarga dan masyarakat yang mengarah pada tatanan masyarakat individualistik terutama di kota besar, menyebabkan lanjut usia kurang mendapat perhatian dan sering dari kehidupan masyarakat atau bahkan menjadi terlantar.

\section{METODE}

\section{Tahapan Kegiatan}

1) Kegiatan yang pertama dilakukan adalah perencanaan kegiatan yang dilakukan setelah adanya permohonan dari paguyuban lansia St.Simeon paroki Gereja St. Lukas Samarinda.

2) Pelaksanaan kegiatan sesuai dengan jadwal yang telah disusun oleh paguyuban lansia St. Simeon, antara lain penyuluhan kesehatan, penimbangan berat badan, pemeriksaan tekanan darah, pemeriksaan asam urat, gula darah sewaktu, kolesterol, dan pemeriksaan kesehatan yang dilakukan oleh dokter rumah sakit Dirgahayu.

3) Kegiatan dibantu oleh mahasiswa STIKES Dirgahayu.

Hasil pemeriksaan ditulis pada kartu peserta

\section{HASIL dan PEMBAHASAN}

Proses penuaan merupakan suatu proses yang pasti, namun untuk mengalami proses penuaan yang sehat merupakan pilihan bagi seorang lansia. Oleh karena itu perlu langkah-langkah konkrit yang harus dilaksanakan secara berkesinambungan dalam upaya meningkatkan derajat 
kesehatan lanjut usia dan mendapatkan kesehatan yang baik, dapat menjadilansia yang mandiri, berprilaku aktif dan produktif serta bermanfaat bagi komunitas.

Tabel 1. Hasil pemeriksaan tekanan darah

\begin{tabular}{lcccc}
\hline Variabel & Frekuensi & $\%$ & Total & $\%$ \\
\hline$\leq$ & & & & \\
$\begin{array}{l}140 / 100 \mathrm{~m} \\
\mathrm{mHg}\end{array}$ & 78 & 58,3 & 134 & 100 \\
$\geq$ & & & & \\
$\begin{array}{l}140 / 100 \mathrm{~m} \\
\mathrm{mHg}\end{array}$ & 56 & 41,79 & 134 & 100 \\
\hline
\end{tabular}

Berdasarkan hasil pemeriksaan dari 134 anggota 56 orang (41,79\%) dengan tekanan darah $\geq 140 \mathrm{mmHg}$.

\section{Tabel 2. Hasil pemeriksaan GDS}

\begin{tabular}{llccc}
\hline Variabel & Frekuensi & $\%$ & Total & $\%$ \\
\hline$\leq 120 \mathrm{mg} / \mathrm{dl}$ & 96 & 71,16 & 134 & 100 \\
$\geq 120 \mathrm{mg} / \mathrm{dl}$ & 38 & 26,86 & 134 & 100 \\
& & & & \\
\hline
\end{tabular}

Berdasarkan hasil pemeriksaan dari 134 anggota 38 orang $(26,86 \%)$ dengan gula darah sewaktu $\geq 120 \mathrm{mmHg}$.

Tabel 3. Hasil pemeriksaan Asam urat

\begin{tabular}{clccc}
\hline Variabel & Frekuensi & $\%$ & Total & $\%$ \\
\hline$\leq 6 \mathrm{mg} / \mathrm{dl}$ & 15 & 11,19 & 134 & 100 \\
$\geq 6 \mathrm{mg} / \mathrm{dl}$ & 119 & 88,81 & 134 & 100 \\
& & & & \\
\hline
\end{tabular}

Berdasarkan hasil pemeriksaan dari 134 anggota 119 orang $(88,81 \%)$ dengan asam urat $\geq 6 \mathrm{mg} / \mathrm{dl}$.

Tabel 4. Hasil pemeriksaan Kolesterol

\begin{tabular}{clccr}
\hline Variabel & Frekuensii & $\%$ & Total & $\%$ \\
\hline$\leq 200 \mathrm{mg} / \mathrm{dl}$ & 47 & 35,07 & 134 & 100 \\
$\geq 200 \mathrm{mg} / \mathrm{dl}$ & 87 & 64,93 & 134 & 100
\end{tabular}

Berdasarkan hasil pemeriksaan dari 134 anggota 87 orang (64,93\%) dengan kolesterol $\geq 200 \mathrm{mg} / \mathrm{dl}$.

Tim pengabdian melakukan diskusi dengan ketua paguyuban lansia St.Simeon paroki gereja St.Lukas Temindung Samarinda. Permasalahan yang ditemukan adalah anggota paguyuban lansia menghendaki agar adanya edukasi dan pemeriksaan kesehatan secara teratur. Kegiatan pengabdian pada masyarakat pada paguyuban lansia St.Simeon dimulai pada tanggal 10 Pebruari 2018 dengan pemeriksaan kesehatan, dan dilanjutkan sesuai jadwal yang sudah ditentukan dengan kegiatan senam lansia, penyuluhan serta pemeriksaan kesehatan antara lain timbang berat badan, pemeriksaan tekanan darah, pemeriksaan gula darah sewaktu, pemeriksaan asam urat dan pemeriksaan kolesterol. Kegiatan berlangsung tanpa halangan yang berarti dan peserta mengikuti kegiatan dengan tertib dan interaktif. Rangkaian pemeriksaan dilaksanakan pada 24 Maret 2018, 17 Nopember 2018. Data yang didapat jumlah lansia yang terdaftar 134 orang, tekanan darah $\geq 140 / 100 \mathrm{mmHg}$ berjumlah 56 orang, gula darah sewaktu $\geq 120 \mathrm{mg} / \mathrm{dl}$ berjumlah 38 orang, asam urat $\geq 6 \mathrm{mg} / \mathrm{dl}$ berjumlah 119 orang, kolesterol $\geq 200$ $\mathrm{mg} / \mathrm{dl}$ berjumlah 87 orang.

\section{Kesimpulan}

Telah dilakukan pengabdian pada masyarakat pada paguyuban lansia St.Simeon oleh tim dari STIKES Dirgahayu yang dilakukan sesuai dengan jadwal yang telah ditentukan. Proses menua berlangsung secara alamiah, terus menerus dan berkesinambungan. Faktor eksternal yang mempengaruhi proses menua adalah asupan makanan, pendidikan, sosial budaya, penyakit infeksi/degeneratif, higiene sanitasi lingkungan, ekonomi dan dukungan keluarga. Faktor eksternal lain yaitu 
kemunduran psikologis seperti sindroma lepas ja atan, perasaan sedih dan sendiri, perubahan status sosial sangat mempengaruhi proses menua pada seseorang.

\section{Saran}

Tim pengabdian menyarankan agar anggota paguyuban lansia St.Simeon di paroki St. Lukas Samarinda dapat memeriksakan kesehatan secara rutin dan dapat mendeteksi risiko penyakit degeneratif secara dini. Pemeriksaan ini diharapkan akan membantu anggota paguyuban untuk meningkatkan derajat kesehatannya.

\section{UCAPAN TERIMA KASIH}

Pelatihan ini dapat berjalan berkat dukungan dari STIKES Dirgahayu sebagai sponsor utama yang memberi dukungan penuh dalam pembiayaan kegiatan sehingga dapat terlaksana dengan baik dan memberikan manfaat yang sebesarnya bagi mitra.

\section{DAFTAR PUSTAKA}

Aziz, alimul.(2009) Konsep Dasar Manusia.Jakarta : Salemba Medika

Brunner \& Suddarth.(2002). Buku Ajar Keperawatan Medikal Bedah. Ed. VIII Jakarta : Penerbit Buku Kedokteran EGC.

Notoatmodjo S. 2010. "Promosi Kesehatan: Teori dan Aplikasi". Jakarta : Rineka Cipta.

Jennifer, Kowalak,. Welsh, Williams. (2011). Buku Ajar Patofisiologi.Alih Bahasa Andry Hartono. Jakarta: BukuKedokteran EGC.

Kementrian Kesehatan RI. Profil Kesehatan Indonesia 2015.

Setiadi.(2008). Konsepdan Proses Keperawatan Keluarga. Yogyakarta : GrahaIlmu.
Sulistyo, A. (2012). Keperawatan Keluarga Konsep Teoridan Praktik Keperawatan. Yogyakarta :GrahaIlmu 